\title{
Night-Time Operations in Transit Systems: Evaluating the Athens Metro Owl Services
}

\author{
Eirini Veliou, Illinois Institute of Technology \\ Konstantinos Kepaptsoglou and Matthew G. Karlaftis \\ National Technical University of Athens
}

\begin{abstract}
Public transport operators make significant efforts toward improving the quality of operations by upgrading and maintaining infrastructure and rolling stock, training personnel, and offering better and more responsive services to passengers. Among these responsive services is the extension of service at night (night-time extension) whose goal is to serve night-time demand for passengers. This paper examines, analyzes, and evaluates the performance and quality of the Athens Metro night-time service extension for a two-month trial period. Based on ridership estimates and extensive passenger satisfaction surveys, results indicate that the night-time extension attracted a considerable number of passengers who previously used their private automobiles for the same trips and that users were highly satisfied with the service.
\end{abstract}

\section{Introduction}

Public transportation systems have long been considered the best alternative to automobile transportation in large urban areas; their ability to carry large numbers of passengers while occupying limited urban space at a lower (unit) cost and with far fewer environmental impacts are advantages that make transit 
suitable and desirable for urban transport operations (Sinha 2003; Vuchic 2004). Demand, however, is closely related to customer satisfaction by the services provided; improved quality of service, such as higher reliability and adequate service frequencies, is critical for shifting passengers to public transportation (Friman and Fellesson 2009; Eboli and Mazzulla 2009).

In this context, public transport operators frequently make significant efforts towards improving the quality of operations by offering new and improved services to passengers. Among these new services is extended operating hours into night, with the goal of serving passengers who otherwise would not use transit (the so-called "transit owl services") (Faria and Smith 1996; Gwiazdzinski 2006; Reinhold and Kearney 2008). Indeed, a number of European, Australian, and U.S. cities have established public transportation night-time operations: Paris, London, Melbourne, and Amsterdam, for example, have late-night bus lines, while the metro systems of Athens, Berlin, Barcelona, Copenhagen, New York, and Washington, D.C. are among those systems that have extended service hours past midnight. Examples of night-time metro operations for European cities appear in Table 1. (The interested reader is referred to ELTIS web portal www.eltis.org for further information on such services in Europe.) Anticipated gains related to transit owl services focus on the potential reduction of auto accidents by decreasing the use of private vehicles at night and averting the combination of drinking and driving. Moreover, such services have a distinct social role since they (a) allow low-cost transportation during night-time hours, (b) can facilitate transit's captive passengers, and (c) may generate new jobs in the transit sector (TRB 1998a).

\section{Table 1. Night-Time Metro Operations for Some European Cities}

\begin{tabular}{lccc}
\hline City & Weekday & Weekend & $\begin{array}{c}\text { Notes on } \\
\text { Weekend Timetable }\end{array}$ \\
\hline Barcelona & $05.00-24.00$ & $05.00-02.00$ & $\begin{array}{c}\text { Friday and Saturday night } \\
\text { Berlin }\end{array}$ \\
Hamburg & $04.00-01.00$ & All night & Friday and Saturday night \\
Lisbon & $06.00-24.00$ & All night & Friday and Saturday night \\
Madrid & $06.00-02.00$ & $06.30-01.00$ & - \\
Munich & $04.10-01.30$ & $04.10-02.30$ & Friday and Saturday night \\
Paris & $05.30-01.15$ & $05.30-02.15$ & Saturday night \\
\hline
\end{tabular}

Source: Metro systems web sites, ELTIS web portal http://www.eltis.org 
While transit owl services are becoming popular in large urban areas, there has been only limited research and in-depth investigation on this topic; Miller (1984), for instance, evaluated and proposed a novel redesign for night-time transit service for Salt Lake City County in the early 1980s. Gwiazdzinski (2006) discussed elements of night-time mobility and transportation services and potentials. In a recent study, Currie and Loader (2009) analyzed night extension of bus services for the Melbourne bus transit system; the authors reported that the extension had a considerable positive effect on overall transit ridership.

In early 2008, the Athens Metro authority extended service for two hours (12:302:30 a.m.) on Fridays and Saturdays for a two-month trial period. Their effort aimed at (a) improving access to recreational/night entertainment areas in downtown Athens that suffer from inadequate road infrastructure and limited parking spaces and (b) providing alternative transportation to people not wanting to use their private automobiles (possibly because of alcohol consumption). It should be noted that while Athens has strong recreational and night-entertainment activities year-round, after-midnight transportation traditionally has been available only to private vehicle and taxi users (prior to the trial extension period).

This paper examines, analyzes, and evaluates the performance and quality of the Athens Metro night extension of service for its two-month trial period. More specifically, based on the results of extensive surveys, ridership estimates and passenger satisfaction are derived, analyzed, and discussed. The remainder of the paper is organized as follows: the next section presents details on the set of surveys undertaken throughout the two-month trial period of the night-time extension. Then, results for ridership, trip characteristics, and passenger satisfaction are presented, analyzed, and discussed. Finally, concluding remarks and a short discussion are offered.

\section{Surveys and Data Collection}

The survey took place at all stations of the Athens Metro system (Figure 1) each Friday and Saturday night from 11:00 p.m. to 2:30 a.m. for a period of 45 days (February 15 - March 29, 2008). It included two parts, with the first part focusing on passenger boardings and transfers and the second on collecting passenger opinions regarding the extension by means of short personal interviews. 
Journal of Public Transportation, Vol. 13, No. 3, 2010

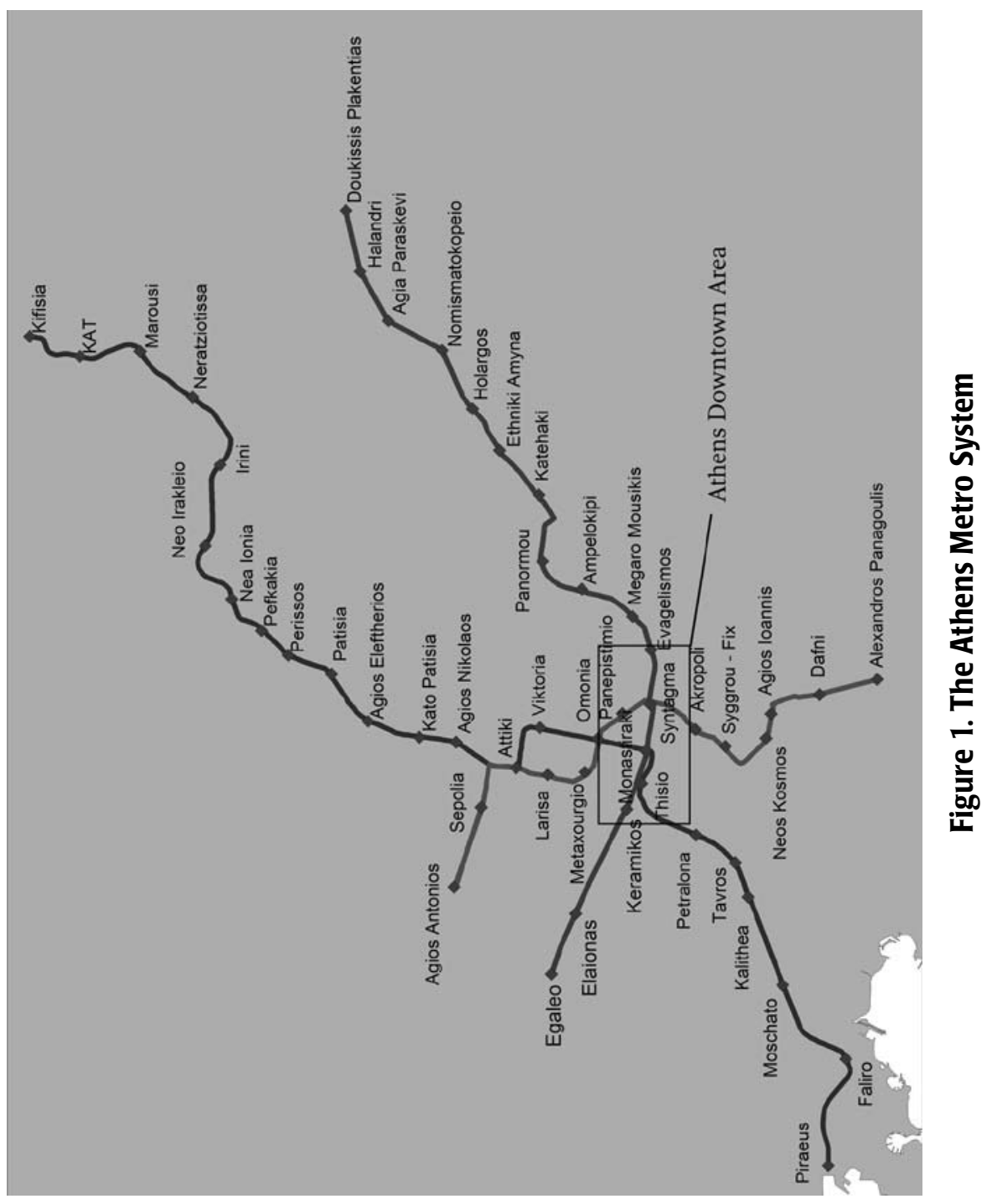




\section{Ridership Survey}

The Athens Metro fare collection system can provide only partial data on ridership, since (a) a considerable percentage of riders (over $50 \%$ for regular, daytime operations) use monthly and annual fare cards that do not need to be validated when entering the Metro system (and therefore could not be estimated without a survey), and (b) single-ride tickets are validated when only entering a station (implying that transfers had to be counted as well). A direct passenger count process was carried out at each Metro station platform by trained personnel located at pre-specified positions of platform entrances. The number of passengers arriving at the platforms was recorded during fixed time intervals (every 15 minutes); in addition, transfers were counted between all three Metro lines on the transfer corridors between platforms. It should be noted that the task of counting transfers required a detailed inspection of the topology of the transfer stations. Finally, the ridership measurement process needed to be thorough, given the requirement for collecting accurate data regarding boardings and transfers at each platform and station.

\section{Passenger Survey}

The second part of the survey included short face-to-face interviews, through which information on passenger and trip characteristics and passenger satisfaction were collected. In particular, collection and analysis of passenger satisfaction using marketing techniques and surveys (TRB 1998b; TRB 1999) has been implemented widely in the last decade for evaluating new transit services; some relevant studies are presented in Iseki and Taylor (2008), Kim and Ulfarsson (2008), Eriksson et al. (2007), McDonnell et al. (2006), Pepper et al. (2003), and Pepper and Ray (1998). Two separate surveys were designed for this purpose, with the first focusing on various trip characteristics (such as travel times, modes used to approach the Metro line, origins and destinations, trip purpose, and so on). The second survey aimed at capturing passenger satisfaction; this was achieved through the part of the interview in which passengers were requested to grade aspects of the night extension on a scale of 1 to 5 . The respondents were selected randomly among passengers waiting to board, and the interviews lasted approximately two minutes. A stratified sampling process (Tryfos 1996) was followed, considering gender and age, and a minimum number of 500 interviews was assumed to be adequate for the purpose of both interview-based surveys (3-5\% of estimated ridership for that time period; this assessment was based on ridership information collected during the first weekend of the passenger ridership survey). However, the willingness of passengers to participate in the surveys led to over 2,000 completed pas- 
senger satisfaction questionnaires and over 2,700 completed trip characteristic interviews. In Table 2, the data collected for each survey are discussed.

\section{Table 2. Collected Data}

\begin{tabular}{ll}
\hline \# Survey Type & Collected Data \\
\hline 1. Ridership Survey & - Boardings per station and platform /15min \\
& $(23: 00-02: 30)$ \\
& - Transfers per station and platform /15 min \\
& $(23: 00-02: 30)$ \\
\hline
\end{tabular}

2. Trip Characteristics

- Origin and destination stations

- Fare type used

- Trip purpose

- Mode used for night-time transportation before the Metro service extension

- Frequency of transit usage

- Reasons for using the Metro system during the nighttime extension period

- Desire to establish a similar extension of service for the Athens bus lines

- Gender, age

3. Passenger Satisfaction

- Trip purpose

- Mode used for night-time transportation previously to the Metro service extension

- Frequency of transit usage in general

- Mode for accessing the Metro system

- Satisfaction with respect to (1: dissatisfied - 5: satisfied for

Security

Frequency

Duration of the extension

Speed

Cleanliness

Fare validation

Connection with other transport means

Overall

- Importance of the above attributes

- Gender, Age 


\section{Ridership}

Figure 2 summarizes ridership for the extended hours; the relatively low ridership for March 7 and 8 (compared to the remainder of the period) is expected since this was a long weekend and Athens inhabitants traditionally take long weekends. As can be seen from Figure 2, ridership increased during the trial period. It can be observed that ridership reached 22,000 passengers on Saturdays. Considering that four trains per hour and direction were scheduled and operated during the extension, the total Metro system capacity was $4 \times 4 \times 1,000=16,000$ passengers/hour or 32,000 passengers during the (two-hour) extension period. This implies that Metro occupancy for the extension period was almost 70 percent, which was considered very good, given that under normal operations, a 15-minute service for a metro system is rather unattractive to passengers.

Figure 3 indicates that ridership during the extension period is comparable to that of Saturday mornings (8:00-10:00 a.m.). Moreover, ridership for the time period before the extension has increased, consistent with the findings of Currie and Loader (2009). Passengers "attracted" by the service extension use the Metro system for both approaching their destination and returning home, while before the extension they were discouraged from doing so and relied on other transportation modes (private vehicles, taxis). As far as ridership is concerned for specific stations, as can be seen in Figure 4, the largest number of boarding passengers is observed in downtown stations next to recreational areas (stations of Monastiraki, Syntagma, and Kerameikos). Other suburban stations (such as Halandri, for example) exhibit low ridership. It is apparent that during the night-time extension, passengers used the Metro system for departing and returning home; these passenger moved from the Athens downtown to the suburbs but usually not vice versa. 


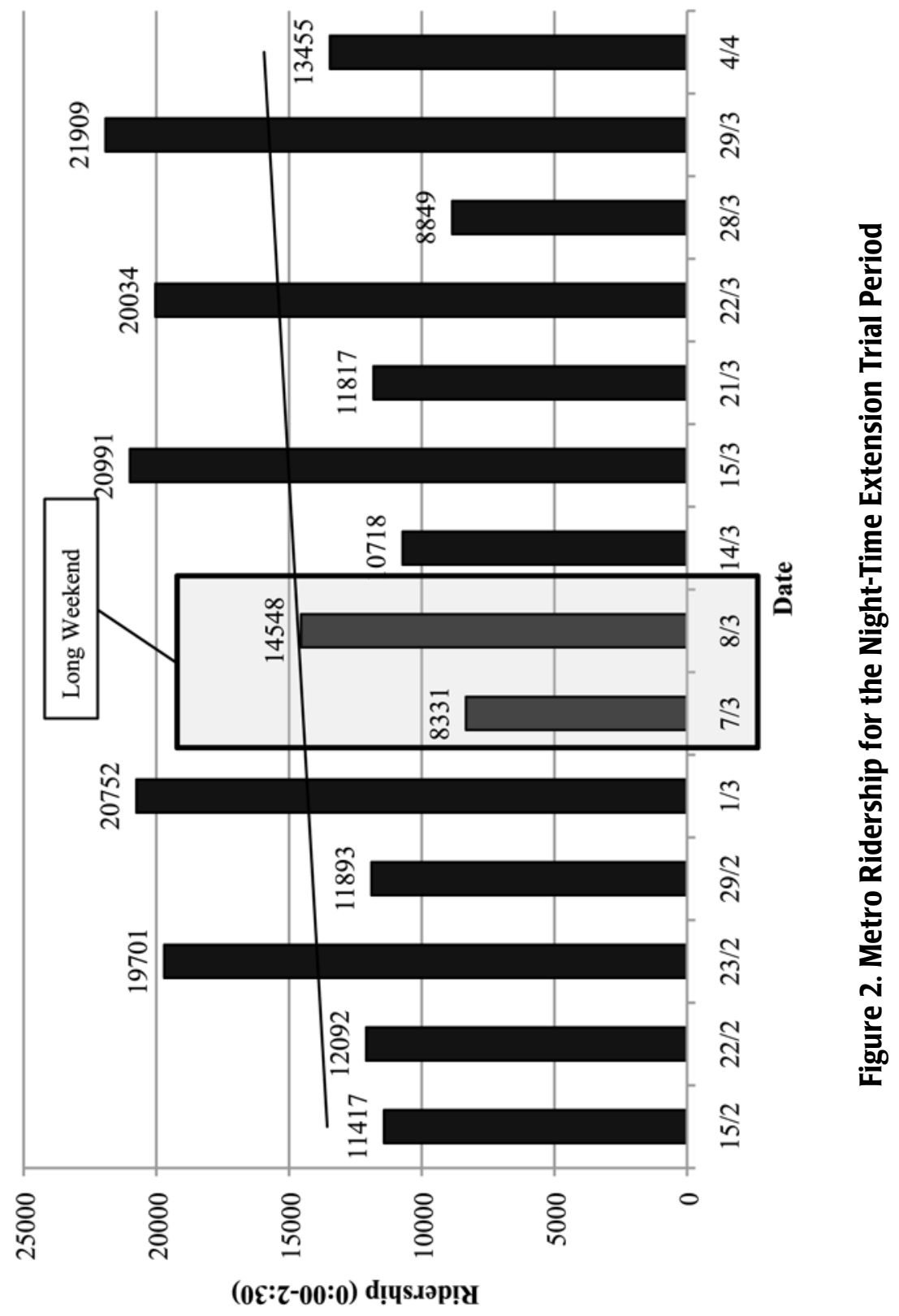




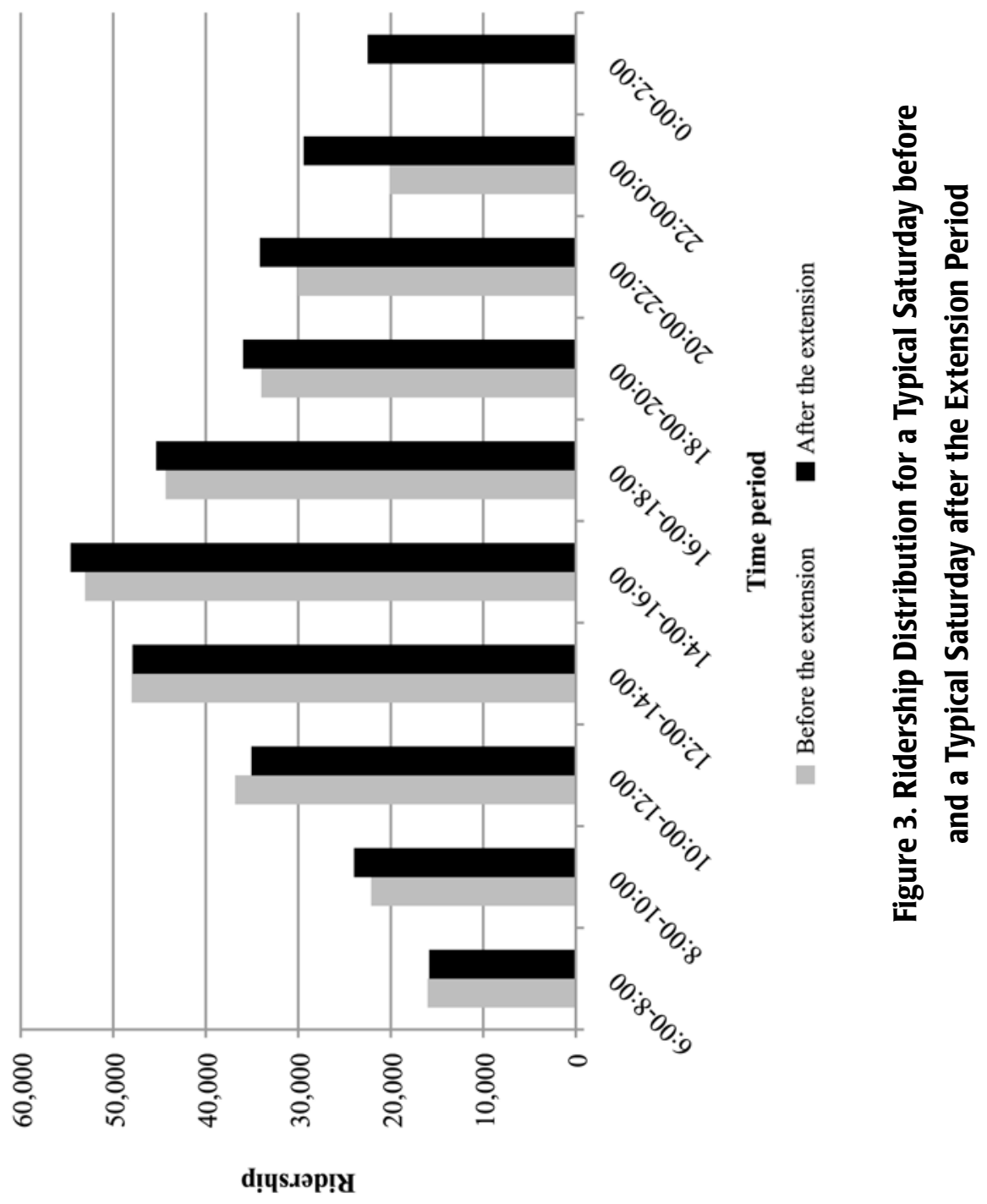


Journal of Public Transportation, Vol. 13, No. 3, 2010

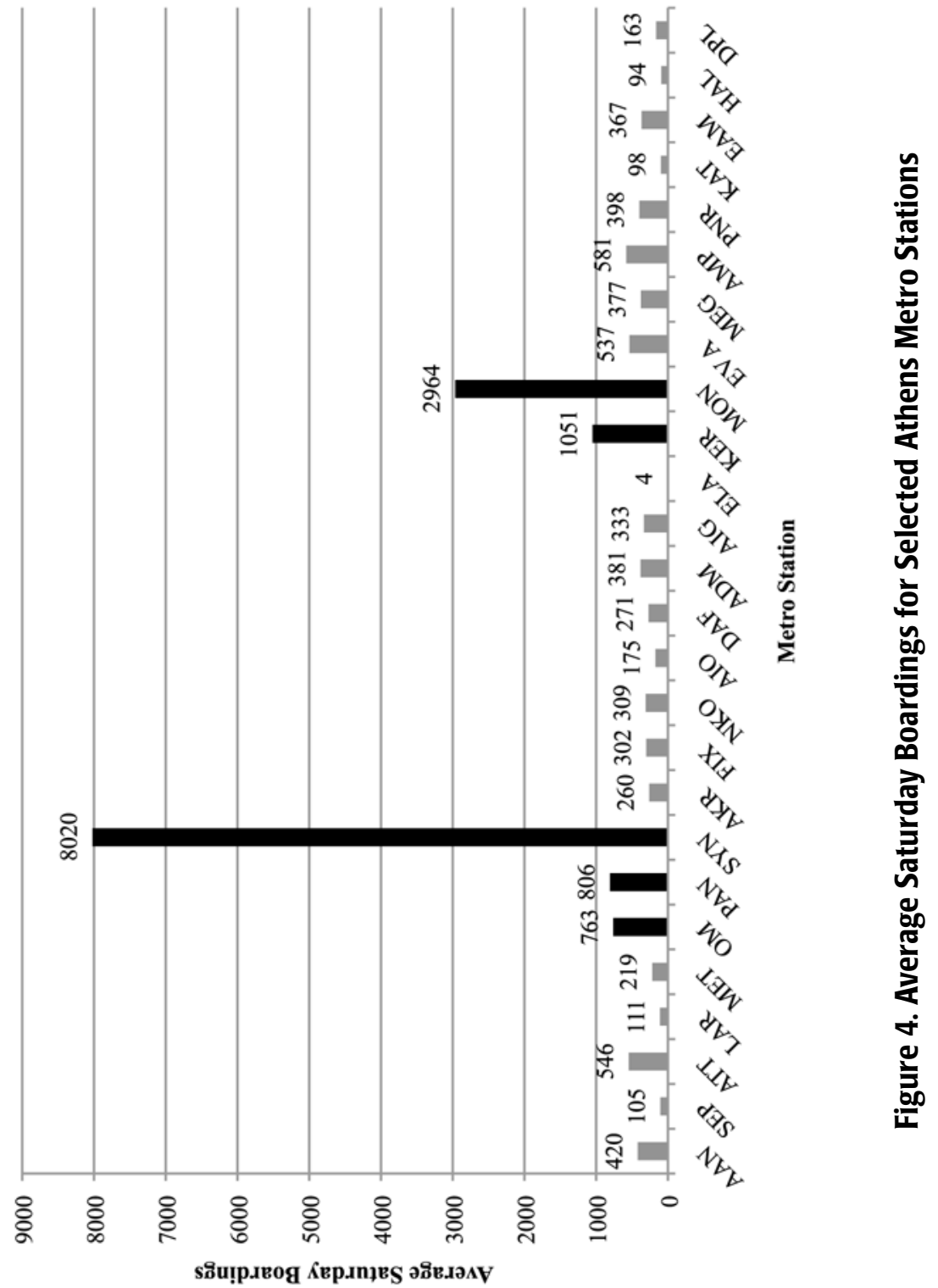




\section{Trip Characteristics and Passenger Preferences}

Obtaining information on trip characteristics and passenger preferences was among the main objectives of the study. It was considered important to study the manner in which passengers used the Metro system during the extension period (combination with other modes, origin, destination, trip purpose and so on), since this could help in improving services and studying mode choice behavior in the pre- and post-extension periods. Results indicate that the majority of passengers were 18 to 30 years old (about 67\%), and over 75 percent of them had entertainment as their trip objective (they either approached or returned from a night entertainment site; see Figures 5 and 6 ). What also is interesting is that most of the passengers (almost 90\%) are regular public transportation users; they are either captive passengers or passengers preferring transit as a convenient alternative to private vehicles. Figure 7 presents passenger mode choice for the same (or similar) trips in the pre-extension period (note that prior to the extension, a very limited number of night-time bus lines existed).

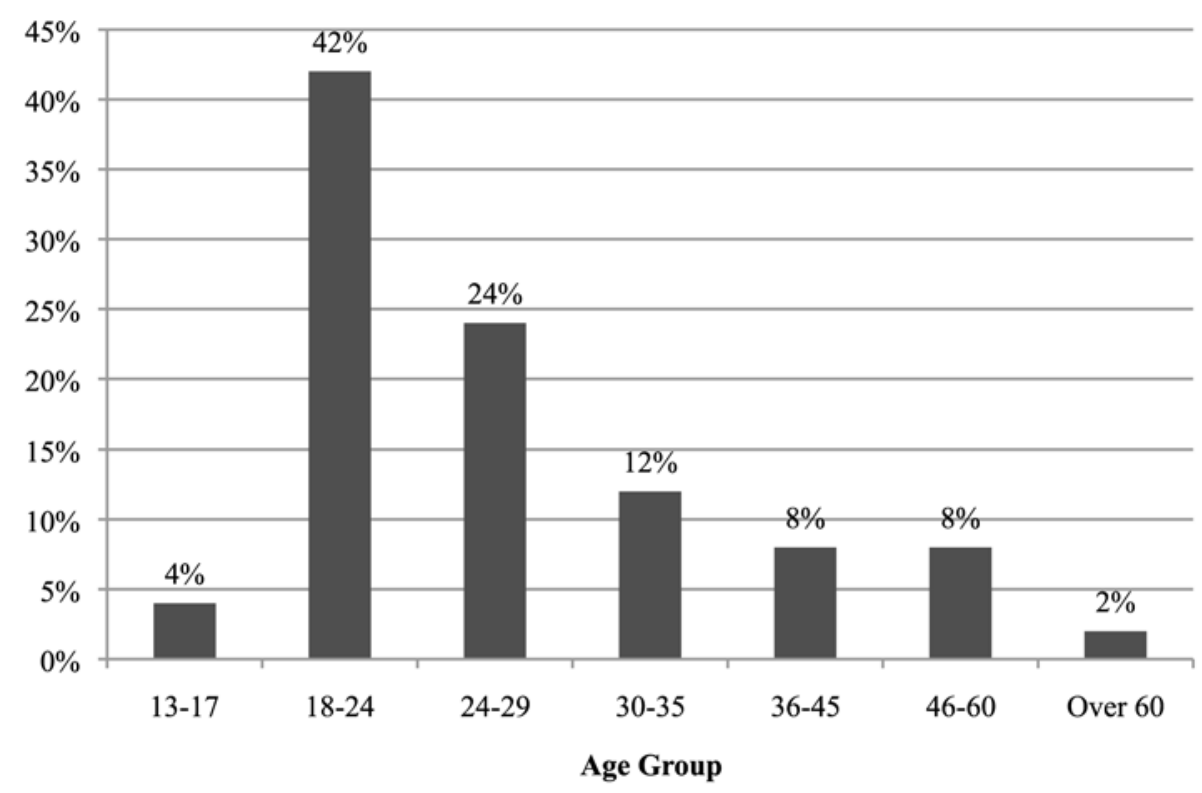

Figure 5. Age Distribution of Respondents 


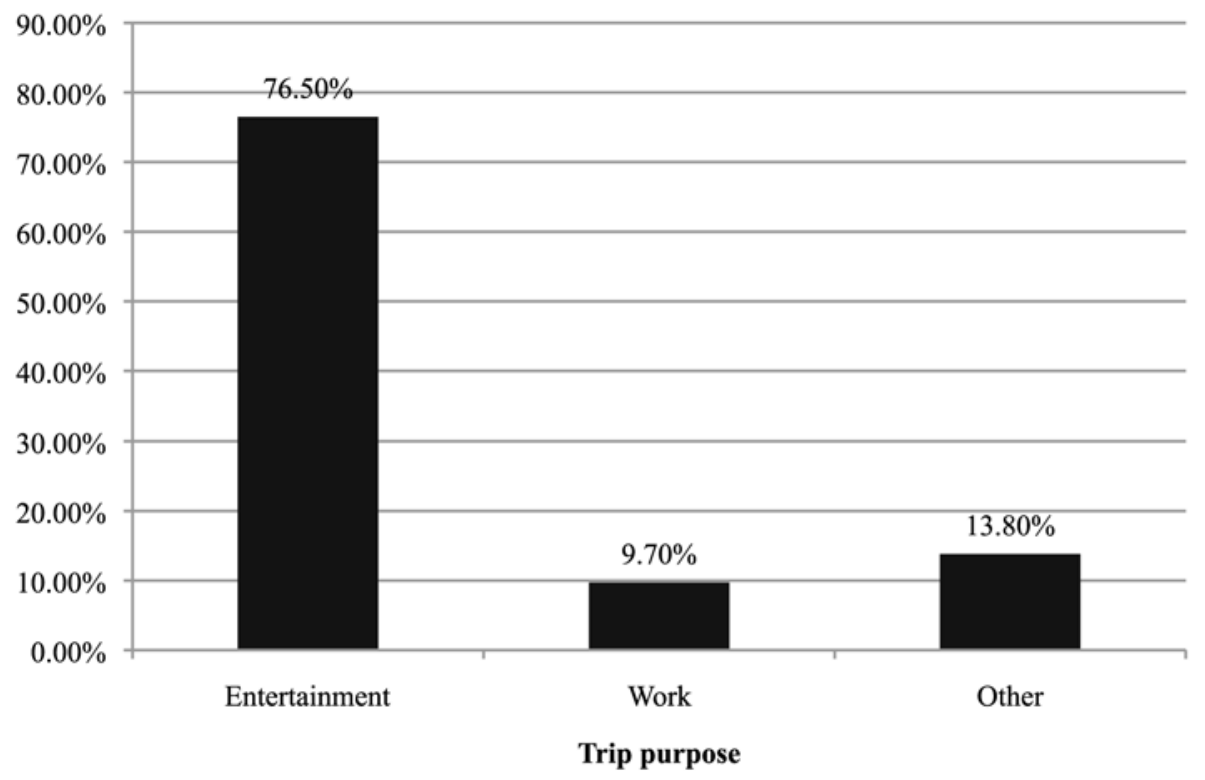

Figure 6. Trip Purpose during Night-Time Service Extension

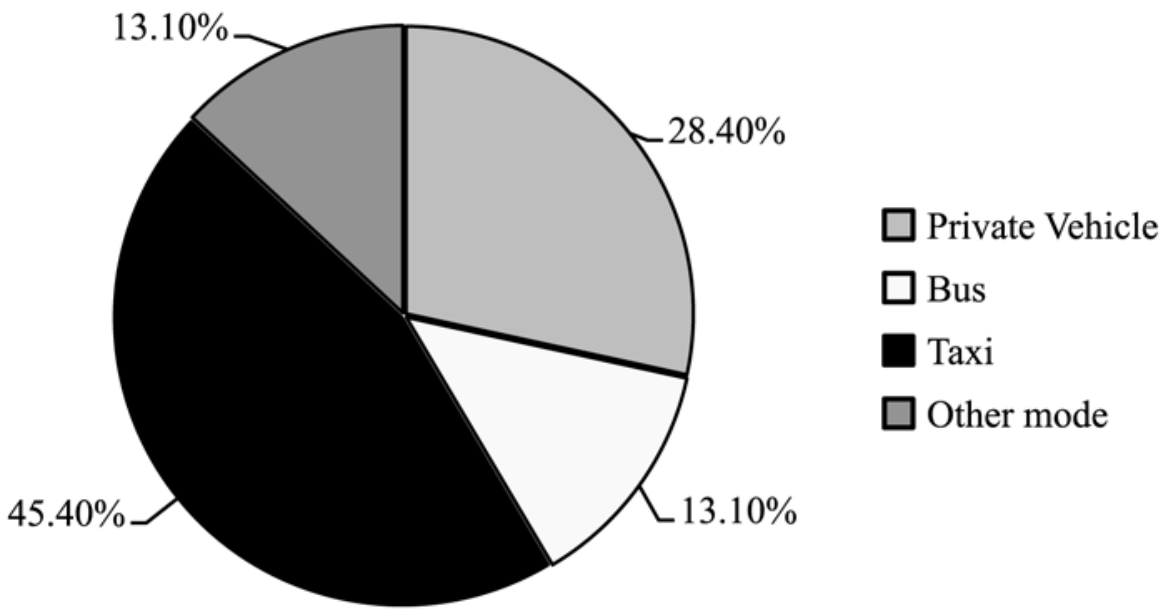

Figure 7. Mode choice prior to Metro System Service Hours Extension 
According to the findings depicted in Figure 5, most passengers in the preextension period used either their private vehicle (almost $30 \%$ ) or taxis (45\%) for night-time transportation. The Metro service extension resulted in an important reduction in private vehicle and taxi usage. For instance, for a Saturday ridership of approximately 22,000 passengers, about 28 percent of them previously used private vehicles. Assuming an average vehicle occupancy rate of 2 (for night-time transportation), this implies that about 3,000 private vehicles do not enter the Athens downtown areas at night, and higher-risk drivers (young and/or intoxicated) prefer the Metro over their automobile. This also leads to savings in fuel consumption; for example, considering a typical EU passenger car consuming around $9 \mathrm{lt}$ of gasoline per $100 \mathrm{~km}$ in the city limits, an average trip length of $8 \mathrm{~km}$ and a cost of $1 € / \mathrm{lt}$, more than $25,000 €$ are saved during each two-hour service extension period from private vehicles alone.

Furthermore, most respondents (70\%) seem to use the Metro as the exclusive mode for their night-time journey; a significant number of the respondents (30\%) use the buses to reach a Metro station and, subsequently, almost 80 percent of the respondents are attracted to the idea of a similar service extension for the bus system. Figure 8 depicts the reasons for preferring the night-time Metro services.

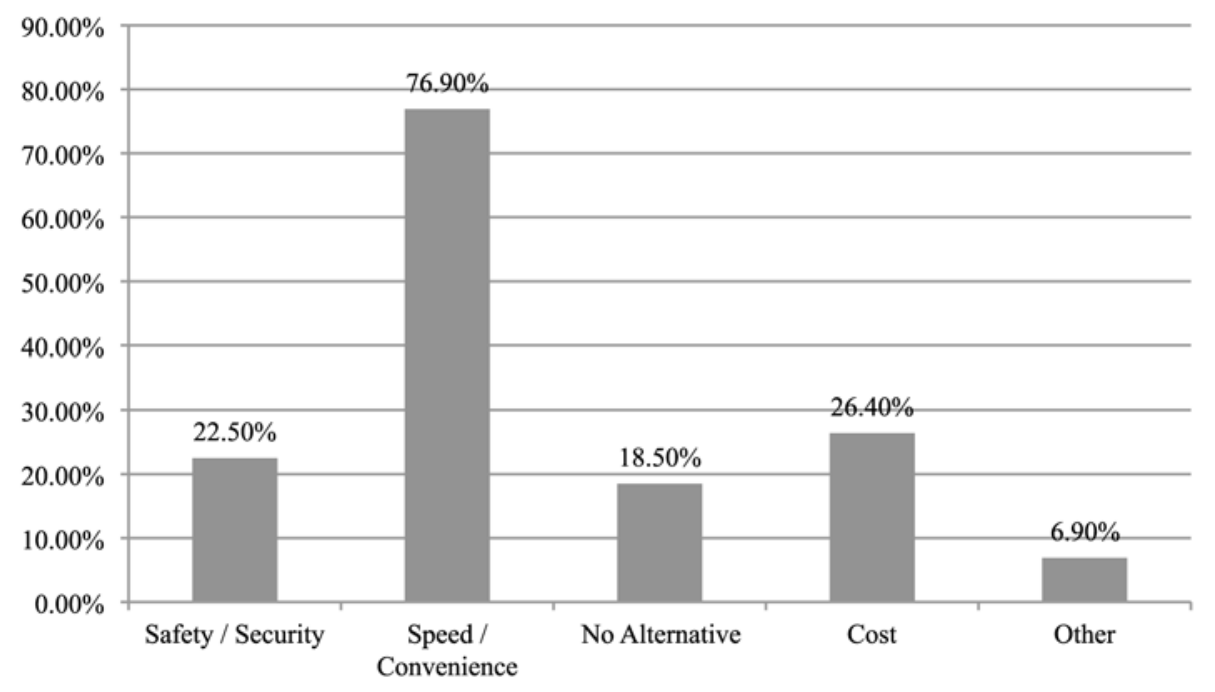

Figure 8. Reasons for Preferring the Metro Night-Time Extension 
The results indicate that the primary reasons for using the extension of the Metro services were convenience and (low) cost. Indeed, night-time traffic congestion in the Athens downtown entertainment areas is a common phenomenon, and parking spaces are limited and very costly. Further, the cost of a Metro ride during the extension period was $0.8 €$, while the estimated travel cost with a private vehicle in a Greek urban area is about $0.3 € / \mathrm{km}$ (not including parking cost) (Poriotis 2000) for a trip of 4-5 km on average (a total of 1.2-1.5 € for a trip), plus a minimum of $€ 10$ for parking. Finally, taxis during late night operations charge a minimum of $2.7 €$.

\section{Passenger Satisfaction}

\section{Overview and Methodology}

This section focuses on the passenger point of view regarding the quality of Metro night-time services (perceived service quality). Passenger opinions on quality attributes such as security, frequency, extension duration, speed, cleanliness, fare validation checks, and connectivity with other modes, as well as their overall satisfaction, were collected on a scale of 1 (not satisfied) to 5 (very satisfied).

A bi-variate correlation approach was used for assessing the importance of the aforementioned quality attributes against overall satisfaction (TRB 1999; Weinstein 2000; Morfoulaki and Papaioannou 2006). A set of random variables $y=\left\{y_{j}\right\}$, obtaining discreet values of 1-5 is assumed; these variables represent satisfaction for corresponding quality attributes. Also, a random variable $y_{n}$ represents total satisfaction for the night-time extension. Bivariate correlation examines the degree of correlation between variable $y_{n}$ and variables $y_{i}$. Since the underlying distribution of random variables is unknown, the non-parametric Kendal's Tau-b test is used, and a significance level of $5 \%$ is used (Washington et al. 2003). The degree of correlation expresses the strength of the effect of each individual element to the overall satisfaction. Knowing the importance and satisfaction for each element, a quadrant analysis is performed (QUATTRO 1998), aiming at indicating any elements in need of improvement during the night-time service extension (QUATTRO 1998). Quadrant analysis is a widely-used tool that graphically represents the importance of a certain attribute to the overall service in terms of respondent satisfaction with this attribute. Importance rates are normalized, and the mean satisfaction rate for each attribute is estimated and again normalized. A scatter plot is then constructed with the importance versus mean satisfaction pairs (for 
each attribute) and divided into four quadrants, where each quadrant indicates whether an attribute is important and/or satisfactory or not.

\section{Preliminary Results}

Figures 9 and 10 present passenger satisfaction results for overall satisfaction and satisfaction with connectivity to other modes.

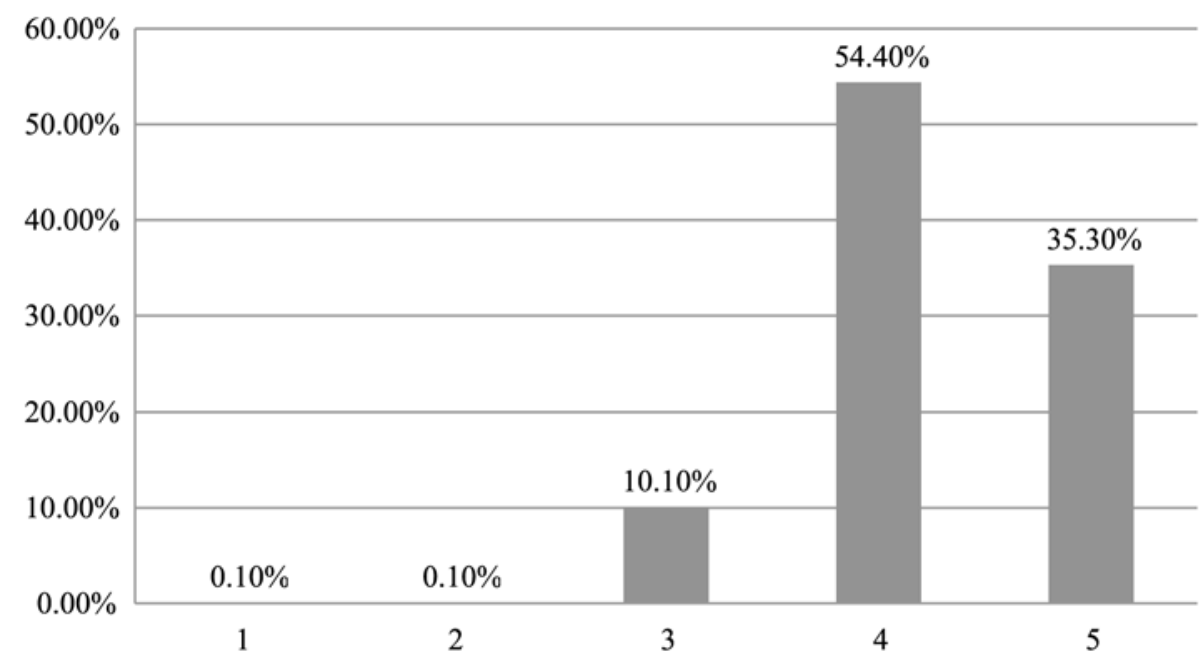

Figure 9. Overall Satisfaction

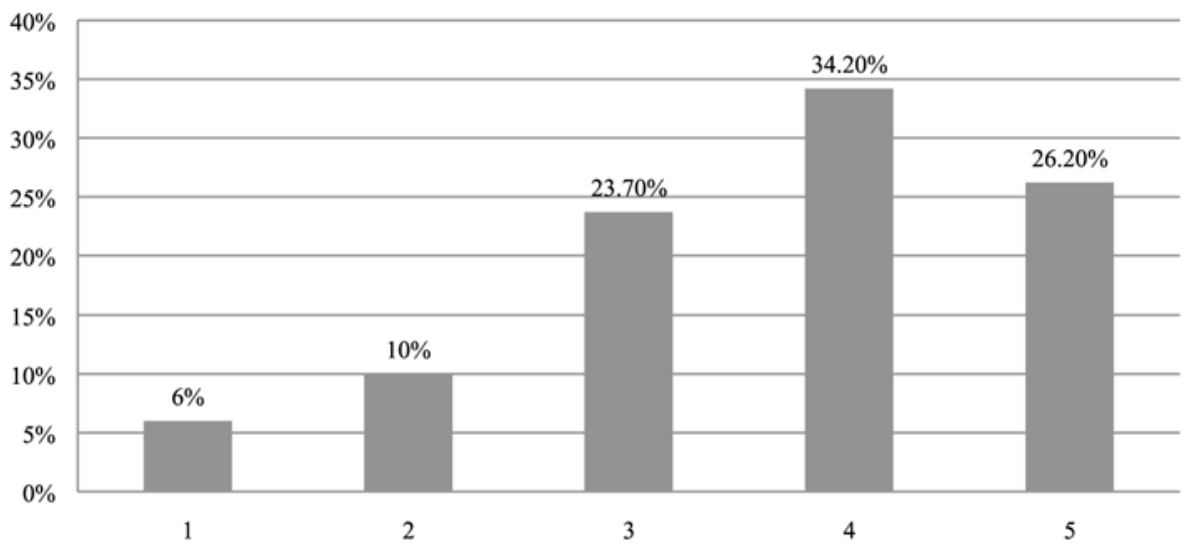

Figure 10. Satisfaction with Connectivity to Other Modes 
As can be seen, overall satisfaction was high, while in the case of connectivity with other modes, a good portion of passengers (about 60\%) were satisfied, despite the lack of bus lines feeding the Metro system at night. Additionally, the preliminary statistical analysis of results indicated, among other results, the following:

1. Passengers were satisfied (score of 4) or very satisfied (score of 5) with security (90\%), speed (96\%), and cleanliness (92\%).

2. Satisfaction with the duration of the extension and the connectivity with other modes was acceptable ( $67 \%$ and $60 \%$, respectively, of the passengers were satisfied or very satisfied).

3. Satisfaction with service frequency was relatively low (54\%).

Overall satisfaction was very high, reaching almost 90 percent of satisfied and very satisfied passengers. It should be noted that the Athens Metro system has a history of providing high quality services; for instance, in 2006, the system was awarded the "Committed to Excellence in Europe" distinction by the European Foundation on Quality Management (EFQM). Frequency-related satisfaction was low; daily service frequency is 2 to 3 minutes during peak and 5 to 7 minutes during off-peak and, as such, a15-minute frequency for the night-time extension was perceived as inadequate by passengers. However, ridership expectations and the need to balance costs (which were expected to be increased due to higher night-shift wage rates) and revenues (of relatively low fares) led to a compromise in the frequency of service.

\section{Importance of Individual Quality Elements}

Results from implementing Kendal's Tau-b for each quality element are shown in Table 3.

\section{Table 3. Results of Implementing Kendal's Tau-b for Each Quality Element $(\alpha=5 \%)$}

\begin{tabular}{lc}
\hline Attribute & $\begin{array}{c}\text { Degree of correlation with } \\
\text { overall satisfaction }\end{array}$ \\
\hline Security & 0.277 \\
Frequency & 0.212 \\
Extension duration & 0.203 \\
Speed & 0.251 \\
Cleanliness & 0.258 \\
Fare validation & 0.193 \\
Connection with other modes & 0.233 \\
\hline
\end{tabular}


Of particular interest is that factors deemed as important (such as frequency) do not appear to strongly affect overall satisfaction. This is probably due to passengers rating overall satisfaction based on those elements that they find positive; as can be intuitively derived from preliminary data, security, frequency and speed exhibit a very strong satisfaction and tend to drive overall satisfaction to a positive level.

\section{Quadrant Analysis}

The scatter plot developed for the quadrant analysis is shown in Figure 11. The quadrant analysis plot presents the relationship between importance and satisfaction of each quality attribute. The vertical axis indicates the normalized value of average satisfaction for each attribute while the horizontal axis its normalized importance.

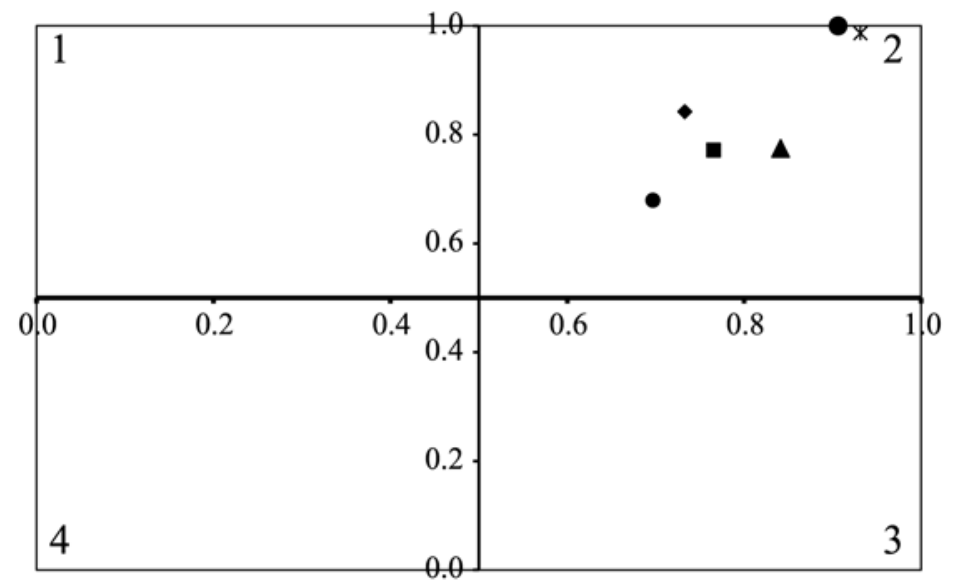

- Frequency

- Duration extension

Speed

Cleanliness

Ticket

Validation

$\Delta$ Combination with other modes

\section{Figure 11. Quadrant Analysis Plot for Metro Extended Service Hours}

The plot is divided into four quadrants: Satisfaction-importance pairs in

- ...quadrant 1 imply low importance and high satisfaction

- ...quadrant 2 imply low importance and satisfaction

- ...quadrant 3 imply high importance and low satisfaction

- ...quadrant 4 imply high importance and satisfaction

Obviously, it is desirable to have as many pairs as possible in quadrants 4 and 1 , while pairs in quadrant 2 may be tolerable. Any attribute whose pair is in quadrant 3 needs immediate remedial measures. As can be inferred from Figure 11, all 
attribute pairs are located in the 4th quadrant. This means that while passengers consider all of them important to the overall quality of the service extension, they are also adequately satisfied by them. Among all attributes, frequency and combination with other modes seem to exhibit the worst performance, by achieving a lower level of satisfaction while being more important compared to attributes such as the duration of the extension and ticket validation.

\section{Conclusions}

The objective of this paper is to present an assessment of the Athens Metro nighttime service extension during weekends. Ridership data, trip characteristics, and passenger opinions were collected through extended surveys in an effort to estimate night-time passenger profiles and overall satisfaction with the new service. Ridership counts indicated that attracted passengers accounted for around 70 percent of provided capacity, while there was a marked ridership increase in the period before the night-time extension. Most passengers were young and had entertainment as their main trip purpose. Convenience and cost were the main reasons for preferring Metro instead of other modes; the extension of service led to a decrease in passenger car and taxi usage, since 28 percent and 45 percent of the passengers used these two modes, respectively. Passenger satisfaction was very high with the exception of service frequency. However, the strong positive effects of security and convenience were critical for obtaining an excellent overall perceived quality for the system. Furthermore, it should be noted that the Athens Metro system exhibits very high passenger satisfaction (an 81.7\% Customer Satisfaction Index according to the European Extended Performance Satisfaction Index [EPSI] method) for its regular (day services), as reported by the managing authority (AMEL 2009) and independent studies (Karlaftis et al. 2005).

The issue of the actual trip purpose (entertainment) affecting the mood and, hence, satisfaction of passengers was not raised in this paper. While this possibly could be a fact, passengers still exhibit lower satisfaction for service frequencies and the duration of the extension, compared to daily services (where for instance, frequency satisfaction exceeds 70\%, according to AMEL [2009]). This is an indication that while passengers do have a positive view of Metro (day and night-time) services and possibly a good mood, they still are not satisfied with elements of night-time operations and, therefore, their opinions are not influenced by their trip purpose. Trip purpose effect on customer satisfaction for night-time operations is a topic to be investigated by future research. 
Overall, during the trial period, the night-time extension attracted a considerable number of passengers, and users were satisfied by the provided services. However, additional measures could prove useful for the extension to be successful in the long run. These could include the initiation of night-time bus feeder service to Metro stations, the improvement of parking facilities around Metro stations, and further discouraging private vehicles from entering the Athens downtown area. In particular, older passengers, currently accustomed to using private vehicles for entertainment-related trips, could be attracted to the Metro system by further improving convenience when accessing Metro stations. Moreover, promotional measures such as advertisement of the night-time Metro service extension and a combination of Metro tickets with other entertainment activities (theater tickets and so on) could attract more passengers to the service.

\section{References}

AMEL. 2009. Customer satisfaction measurement report. Athens Metro Authority Official Web Site, http://www.amel.gr/index.php?id=69\&L=1\%27, last accessed December 2009. (in Greek).

Currie, G., and C. Loader. 2009. High ridership growth from extended transit service hour: An exploration of causes. Paper presented at the 88th Transportation Research Board Annual Meeting, January 11-15, Washington, DC.

Dimitriou, D., M. G. Karlaftis, and A. Stathopoulos. 2006. Sampling for public transport during large events: A venue-based approach. Proceedings of the 85th Transportation Research Board Annual Meeting, Washington DC.

Eboli, L., and G. Mazzulla. 2009. A new customer satisfaction index for evaluating transit service quality. Journal of Public Transportation 12(3): 21-37.

Eriksson, L., M. Friman, and A-C. Norman. 2007. Electronic service quality: Public transport information on the internet. Journal of Public Transportation 10(3): 35-46.

Faria, D.A., and W. Smith. 1996. Planning innovative public transportation systems for Arlington, Texas. Transportation Research Record 1521: 20-28.

Freeman, M., and M. Fellesson. 2009. Service supply and customer satisfaction in public transportation: The quality paradox. Journal of Public Transportation 12(5): 57-69. 
Gwiazdzinski, L. 2006. "NOCTURNES" Nighttime mobility services and transportation systems in Europe and on other continents. Proceedings of the 2006 European Transport Conference, Strasbourg, Sep 18-20.

Iseki, H., and B. Taylor. 2008. Style versus service? An analysis of user perceptions of transit stops and stations in Los Angeles. Paper presented at the 87th Transportation Research Board Annual Meeting, January 13-17, Washington, DC.

Karlaftis, M., D. Dimitriou, K. Kepaptsoglou, and N. Giannoulis. 2005. Evaluation of the Athens fixed route public transportation modes quality of services. Proceedings of the 1st Conference on the Development of Rail Transportation in Greece, Athens, Greece (in Greek).

Kim, S., and G. Ulfarsson. 2008. Riding the light rails: Analysis of user satisfaction and personal, temporal, and environmental factors. Paper presented at the 87th Transportation Research Board Annual Meeting, January 13-17, Washington, DC.

McDonnell, S., S. Ferreira, and F. Convery. 2006. Impact of bus priority attributes on catchment area residents in Dublin, Ireland. Journal of Public Transportation 9(3): 137-162.

Miller, R.C. 1984. Design of a nighttime transit system for Salt Lake County, Utah (abridgment). Transportation Research Record 922: 73-76.

Morfoulaki, M., and P. Papaioannou. 2006. Measuring customer satisfaction index: Survey of Thessaloniki, Greece. Paper presented at the 85th Transportation Research Board Annual Meeting, January 22-26, Washington, DC.

Pepper, J., and A. Ray. 1998. NJ transit's midtown direct service: Are customers satisfied? Transportation Research Record 1623: 121-126.

Pepper, J., G. Spitz, and T. Adler. 2003. Customer perspectives on multilevel coaches for increasing rail system capacity. Transportation Research Record 1838: 19-29.

Poriotis, N. 2000. A novel methodology for estimating vehicle operating costs in Greece. Paper presented at the 1st International Conference on Transportation Research in Greece, Athens, Greece (in Greek).

QUATTRO.1998. QUATTRO Final Report, http://www2. eur.nl/ quattro/ final _report /QuattroFinal Report.pdf, EU. 
Reinhold,T., and A. T. Kearney. 2008. More passengers and reduced costs: The optimization of the Berlin Public Transport Network. Journal of Public Transportation 11(3): $57-78$

Sinha, K.C. 2003. Sustainability and urban public transportation. Journal of Transportation Engineering 129(4): 331-341

TRB. 1998a. Using public transportation to reduce the economic, social and human costs of personal immobility. TCRP Web Document 7, Washington, DC.

TRB. 1998b. A handbook: Integrating market research into transit management. TCRP Report 37, Washington, DC.

TRB. 1999. A handbook for measuring customer satisfaction and service quality. TCRP Report 47, National Academy of Sciences, Washington, DC.

Tryfos. P. 1996. Sampling Methods for Applied Research, John Wiley and Sons, New Jersey.

Vuchic, V. 2004. Urban Transit: Operations, Planning and Economics. John Wiley and Sons, Inc., Hoboken, NJ.

Washington, S., M. G. Karlaftis, and F. L. Mannering. 2003. Statistical and Econometric Methods for Transportation Data Analysis. Boca Raton, FL: Chapman and Hall/CRC Press.

Weinstein, A. 2000. Customer satisfaction among transit riders: How customers rank the relative importance of various service attributes. Transportation Research Record 1735: 123-132

\section{About the Authors}

EIRINI VELIOU (veliou@hotmail.com) is a graduate student at the Illinois Institute of Technology. She holds a diploma in Civil Engineering from the National Technical University of Athens. Her research interests include transportation planning and design and railway and geotechnical design.

KonStANTINOS KePAPTSOGLou (kkepap@central.ntua.gr) is a researcher at the National Technical University of Athens (NTUA). He holds a Civil Engineering diploma from the NTUA, a master's degree from Purdue University, and a Ph.D. from the NTUA. His research interests include public transportation, transportation planning, railway planning, and design and operations research. 
MAtthew G. KARLAftis (mgk@central.ntua.gr) is an Associate Professor at the School of Civil Engineering of the National Technical University of Athens. His educational background includes B.Sc. and M.Sc. degrees from the University of Miami and a Ph.D. from Purdue University. His research has focused on a variety of aspects related to transportation planning, traffic engineering, operations research, and statistics. He is a co-author of over 70 publications in peer reviewed journals and an area editor of ASCE's Journal of Transportation Engineering. 